\section{Revista de Literatura, História e Memória}

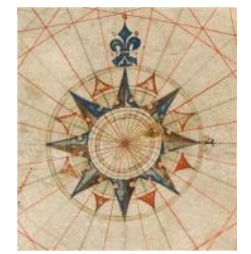

Seção: Pesquisa em Letras no contexto Latino-americano e Literatura, Ensino e Cultura

ISSN 1983-1498

VOL. 17 - No 29 - 2021

U N I O E S T E / CA S C A V E L - p. 232-244

\title{
SAMUEL BECKETT E O IRRACIONALISMO COMO EXPRESSÃO IDEOLÓGICA DA BURGUESIA ${ }^{1}$
}

\author{
Samuel Beckett and the irrationalism as the ideological \\ expression of the bourgeoisie
}

\author{
Ulisses Augusto Guimarães $\mathrm{Maciel}^{2}$
}

RESUMO: A partir de uma realidade devastada pelos extremos do pensamento reacionário da primeira metade do século XX, Samuel Beckett (1906-1983) propõe uma ruptura com a tradição realista, de modo a evidenciar o avançado estágio de decadência do modelo ideológico burguês. No presente artigo, discutimos a influência desse contexto histórico-social no processo de composição da literatura beckettiana entre os anos de 1932 e 1953, sendo Dream of fair to middling women (1932), Murphy (1939), Molloy (1951), Malone morre (1951) e O inominável (1953) os romances que orientaram este estudo. Nesta análise, estabelecemos diálogo com a filosofia de Georgy Lukàcs (1885-1971), dando ênfase às obras Marxismo e a teoria da literatura (1968) e The meaning of contemporary Realism (1969).

PALAVRAS-CHAVE: Beckett; Decadência; Irracionalismo; Realismo.

ABSTRACT: From a reality devastated by the extremes of reactionary thought in the first half of the twentieth century, Samuel Beckett (1906-1983) proposes a break with the realist tradition, in order to evince the advanced stage of the bourgeoisie's ideological decadence. In the present article we discuss precisely the influence of this historical-social context on the composition process of the Beckettian literature between 1932 and 1953, being these, Dream of fair to middling women (1932), Murphy (1939), Molloy (1951), Malone dies (1951) and The Unnamable (1953), the novels which guided this study in dialogue with the philosophy of Georg Lukàcs (1885-1971), giving emphasis to the works Marxismo e a teoria da literatura (1968) and The meaning of contemporary Realism (1963).

KEYWORDS: Beckett; Decadence; Irrationalism; Realism.

Em seu primeiro romance, Dream of fair to middling women (escrito em 1932, publicado em 1992), Samuel Beckett pressupõe o lugar do leitor na recepção de sua obra: "The experience of my reader shall be between the phrases, in the silence, communicated by the intervals, not the terms, of the statement, [...] his experience shall be the menace, the miracle, the memory, of an unspeakable trajectory" (1993, p. 138). ${ }^{3}$ O narrador não deixa dúvidas sobre a natureza do texto, nem ignora a relação cada vez mais perturbadora diante de

\footnotetext{
${ }^{1}$ Este artigo está vinculado à pesquisa de doutorado "Samuel Beckett e a decadência da ordem burguesa, financiada pela CAPES.

${ }^{2}$ Doutorando no programa de Pós-Graduação em Letras: linguagens e representações da UESC. Mestre (2016) pelo de Programa de Pós-Graduação em Letras da UFES. Graduado em Letras-Inglês (UFES, 2012), Professor de língua inglesa da rede municipal de ensino de Serra

${ }^{3}$ A experiência de meu leitor estará entre frases, no silêncio, comunicado pelos intervalos, e não pelos termos do enunciado, $[\ldots]$ sua experiência será a ameaça, o milagre, a memória, de uma trajetória não falável (BECKETT apud BERRETTINI, 2004, p. 105).
} 
uma escrita que desafia, em si mesma, os limites da compreensão e da capacidade de ordenação do sujeito burguês, em seu método de racionalização do mundo. Ao propor a construção de uma narrativa que fracasse diante do processo de avançada decadência ideológica, o autor evidencia o rompimento das estruturas do romance, que passam a não corresponder às demandas da tradição realista, expondo, em certa medida, a intervenção das forças reacionárias na transformação do pensamento burguês no período posterior a 1848 .

Essa ruptura com a forma do romance enquanto gênero de expressão da classe burguesa é tema recorrente nos principais estudos sobre a obra beckettiana. No Brasil, temos o trabalho de Fábio de Souza Andrade, Samuel Beckett: o silêncio possível (2001), que explicita: "a ficção de Beckett institui uma nova ordem de realismo que reconstrói na linguagem a falência do sujeito burguês, a dissolução dos indivíduos como sedes da reflexão, perdidos num mundo coisificado" (2001, p. 30). Mas pouco encontramos, na crítica dedicada à sua obra, de uma referência direta ao irracionalismo e aos impactos dessa conjuntura social, cultural e histórica na trajetória que leva o autor a compor uma obra que se apresenta enquanto processo de afastamento do modelo proposto pelo romance tradicional.

Gyorgy Lukàcs nos traz, em $O$ romance como epopeia burguesa uma visão clara do que entendemos por tradição romanesca, uma literatura, a princípio, fundada dentro dos moldes culturais da burguesia em contradição ao modelo medieval. Modelo que, na fase da decadência, transforma-se em instrumento ideológico de oposição à classe trabalhadora.

\footnotetext{
A apologia se torna o traço cada vez mais predominante da ideologia burguesa: quanto mais emergem de modo nítido as contradições do capitalismo, tanto mais grosseiros se tornam os meios utilizados para glorificá-lo de modo mentiroso e para caluniar o proletariado revolucionário [...] (2009, p. 228).
}

É a partir dessa movimentação que formulamos a compreensão do que denominamos aqui irracionalismo: uma força contrária ao empreendimento progressista proposto pela fase revolucionária da burguesia, da qual a razão surge cada vez mais desacreditada enquanto instrumento de compreensão do mundo. Ou como define Carlos Nelson Coutinho: "as tendências progressistas, antes decisivas, passam a subordinar-se a um movimento que inverte todos os fatores de progresso [...] ao transformá-los em fonte do aumento cada vez maior da alienação humana" (2010, p. 21).

Gyorgy Lukács, em uma exposição crítica sobre a ideologia do modernismo, considera também que: "The desintegration of personality is matched by a desintegration of the outer world. [...] For the identification of abstract and concrete human potentiality rests on the 
assumption that the objective world is inherently inexplicable" $\left(1969\right.$, p. 25). ${ }^{4}$ A desintegração do romance realista é apontada como forma de se fazer enxergar a desintegração própria do mundo, que não mais se enquadra sob a perspectiva do controle racional. Nessa conjuntura, o modernismo surge como ocupação de um espaço que até então se encontrava aberto para o desenvolvimento do irracionalismo enquanto principal corrente do pensamento capitalista na modernidade.

Mesmo não perdendo de vista as contradições do filósofo húngaro em sua teoria sobre o romance, são de importância fundamental para este texto os argumentos apresentados nas obras Marxismo e a teoria da literatura (reunião de ensaios escritos entre as décadas de 1930 e 1940, com primeira edição publicada no Brasil em 1968 e segunda edição publicada em 2010) e The meaning of contemporary realism (escrito e publicado em alemão em 1956 e publicado em inglês em 1963). Essas reflexões tornam-se base relevante na busca pela compreensão do contexto da decadência da ordem burguesa, assim como auxiliam na identificação da influência de tal processo no projeto literário de Samuel Beckett.

O autor irlandês, no esforço por compor uma escrita que nos leve a pensar a literatura na contramão do irracionalismo, o faz de maneira a negar a superficialidade descritiva do naturalismo enquanto representação artística do fenômeno social que traça os caminhos da filosofia ocidental até a era das catástrofes representada pelo nazi-fascismo europeu. Desse modo, quando Lukàcs defende que, para o verdadeiro realista, o tema é produzido e fornecido pelo desenvolvimento histórico-social (2010, p. 83), nos força a destacar o fato de que Samuel Beckett inicia seu processo criativo depois da Primeira Guerra Mundial, intensificando-o consideravelmente no fim da década de quarenta, com o término da Segunda Grande Guerra. Em um cenário de genocídio em escala industrial e com a Europa amplamente destruída, não podemos deixar de observar que o filósofo equivoca-se, ou minimamente perde sua referencialidade histórica, quando classifica Molloy como atenuante da realidade, um fluxo de consciência de um sujeito retardado ou um idiota ao extremo: "In Becketts's novel we have [...] an image of the utmost human degradation - an idiot's vegetative existence. Then, as help is imminent from a mysterious unspecified source, the rescuer himself sinks into idiocy." (LUKÀCS, 1969 p. 31-32). ${ }^{5}$

Na obra Lukàcs, Proust e Kafka: literatura e sociedade no século XX, Carlos Nelson

\footnotetext{
4 A desintegração da personalidade é acompanhada por uma desintegração do mundo exterior. [...] A identificação da potencialidade humana, abstrata e concreta, repousa na suposição de que o mundo objetivo é inerentemente inexplicável (nossa tradução).

${ }^{5}$ No romance de Beckett nós temos [...] uma imagem da máxima degradação humana - a existência vegetativa de um idiota. Então, com a iminente ajuda de uma fonte misteriosa não especificada, o personagem responsável pelo resgate se encontra, ele mesmo, afundado na idiotice (nossa tradução).
} 
Coutinho também chama a atenção para sua divergência com a avaliação substancialmente negativa que o pensador húngaro apresenta sobre algumas literaturas do século XX. Em um trecho Coutinho destaca:

[...] quando ele (Lukàcs) afirma que "o nada de Beckett é um mero jogo com abismos fictícios, aos quais não mais corresponde algo de essencial na realidade histórica[...]" provavelmente porque o perigo da guerra teria sido superado graças à ação dos "partidários da paz", certamente não faz jus nem a sua aguda inteligência nem ao seu espírito crítico" (COUTINHO, 2005, p. 36).

O que não quer dizer que a ficção beckettiana não seja de fato a expressão de uma subjetividade decadente. Mas o ponto central para nosso argumento se dá através da perspectiva que assumimos quando executada a leitura de sua obra. Beckett, ou contrário do que sugere Lukàcs, não busca projetar um modelo de sociedade, mas potencializar a experiência de uma realidade pautada pelo desenvolvimento irracionalista. Consequentemente, seus textos não devem ser lidos a partir da ótica do sujeito narrado, mas do objeto, ou melhor, do processo de objetificação do homem, que, inserido em uma lógica da distração, deixa-se seduzir por um sistema de auto-degradação. E Lukàcs compreende esse processo como poucos pensadores de sua época. Quando se distancia de uma análise direta da literatura de Beckett, ele diz: “A inumanidade da sociedade não é uma segunda natureza que transcenda os homens, mas o aspecto particular no qual se manifestam as novas relações entre os homens, criadas pelo pleno desenvolvimento do capitalismo" (2010, p. 199). Tais relações estão representadas por Samuel Beckett desde o primeiro momento, mas destacamos, em Murphy, um trecho que exemplifica bem esse processo de coisificação ou, até mesmo, "nadificação" do humano:

Cooper took the packet of ash from his pocket, where earlier in the evening he had put it for greater security, and threw it angrily at a man who had given him great offence. It bounced, burst, off the wall on to the floor, where at once it became the object of much dribbling, passing, trapping, shooting punching, heading and even some recognition from the gentleman's code. By closing time the body, mind and soul of Murphy were freely distributed over the floor of the saloon; and before another dayspring greyened the earth had been swept away with the sand, the beer, the butts, the glass, the matches, the spits, the vomit (BECKETT, 1993, p. 154). ${ }^{6}$

\footnotetext{
${ }^{6}$ Cooper apanhou o pacote de cinzas do bolso, onde, por razões de segurança, o deixara mais cedo na mesma noite, e atirou-o descontrolado na direção de um homem que o ofendera gravemente. O pacote voou, explodiu contra a parede, espalhando-se pelo chão onde de imediato se tornou objeto dos golpes mais variados, pontapés, esquivas, socos, cabeçadas e até alguma consideração pelo código de cavalheirismo. Na hora de fechar, o corpo, o espírito e a alma de Murphy estavam livremente distribuídos pelo chão do pub; e, antes que a aurora viesse
} 
O último desejo do protagonista, expressado com o agravamento de uma nota suicida, resulta na mais completa indiferença de Cooper, que, ao se envolver em uma briga de bar, acaba por arremessar o envelope com as cinzas de Murphy na face de quem o ofendera. Murphy, então, não tendo o pedido atendido, encerra sua participação na narrativa. E seus restos descartados, juntamente com os mais variados dejetos encontrados sobre o chão do estabelecimento, eliminam qualquer referência à sua humanidade.

Ao retornarmos nossa atenção a Molloy, vemos um processo semelhante: um movimento de aproximação entre o protagonista, que se nega a assimilar a ordem imposta pelo mundo exterior; e Moran, o agente de costumes burgueses, que, no transcorrer de sua jornada em busca por Molloy, perde os traços característicos que o definem no início da narrativa. Ao terminarmos a leitura do livro, mal podemos distinguir entre um e outro, o que dá uma falsa sensação de circularidade. Mas é importante pensarmos que Molloy controla seu destino, e isso não ocorre com Moran, que é arrastado, como que involuntariamente, por um caminho sem volta, que curiosamente se encerra no ponto em que começou, sua residência. Moran representa o sujeito burocratizado da modernidade. Sua vida está marcada por rituais sem sentido, cujo objetivo ele desconhece: "For how can you decide on the way of setting out if you do not first know where you are going, or at least with what purpose you are going there?” (BECKETT, 2003, p. 99). ${ }^{7}$ O personagem, ao se interrogar, logo após receber a ordem de resgatar Molloy, apresenta uma resposta que a princípio não preenche as lacunas escancaradas intencionalmente pela narrativa. Durante a leitura do texto, a única coisa que se reconhece é a condição do homem desprovido de sua grandeza, o afastamento da força alienante encarregada de desviar a humanidade da urgência de suas ações, imprimindo uma espécie de letargia generalizada. Das palavras de Moran, destacamos: "But the idea of ageing was not exactly the one which offered itself to me. And what I saw was more like a crumbling, a frenzied collapsing of all that had always protected me from all I was condemned to be" (BECKETT, 2003, p. 149). ${ }^{8}$

Em ambos os romances, pode-se reconhecer a ruptura para com os moldes estruturais do realismo tradicional. No entanto, Murphy sustenta a presença de um narrador onisciente, responsável pelo descrever das cenas. Em Molloy, nem mesmo o narrador escapa ao processo

outra vez acinzentar a terra, havia sido varrido fora, com a areia, a cerveja, as bitucas, os copos, os fósforos, o cuspe, e o vômito. (BECKETT, 2013, p. 215).

${ }^{7}$ Pois como decidir a maneira de partir se não se sabe de antemão aonde se vai, ou pelo menos com que objetivo se vai"? (BECKETT, 2007, p. 139)

${ }^{8}$ Mas a ideia de envelhecimento não era exatamente a que se apresentava a mim então. E o que via se parecia mais a um esmigalhamento, a um desmoronamento raivoso de tudo aquilo que desde sempre me protegera daquilo que desde sempre estava condenado a ser” (BECKETT, 2007, p. 203). 
de desconstrução do romance burguês. É essa desconstrução que, a nosso entender, se apresenta enquanto abertura para o entendimento da diferença, ou daquilo que, diferente do ser enquanto identidade de si, possa ser compreendido como o outro. Nesse aspecto, nossa análise dialoga com a definição apresentada por Shane Weller no livro Modernism and Nihilism: "Deconstruction is not an enclosure in nothingness, but an openness towards the other" (2011, p. 144) ${ }^{9}$. Outra marca importante são as consequências de tal desconstrução. Longe de uma consciência alienada, os personagens demonstram certa clareza diante do estado das coisas quando afirmam, por exemplo, "to him who has nothing it is forbidden not to relish filth" (BECKETT, 2003, p. 24) ${ }^{10}$, expondo uma distinção entre as convenções em torno dos que têm, em oposição aos que nada têm. Configura-se uma projeção da fala, a sua imediata relação entre os sujeitos membros de uma sociedade submetida aos impactos do capitalismo tardio. Em outro momento, Molloy retoma a ironia para tratar de si como representação do homem objetificado e, novamente, o que se evidencia não é a estupidez ou idiotice, como afirma Lukàcs, mas a clareza de quem resiste:

My life, my life, now I speak of it as of something over, now as of a joke which still goes on, and it is neither, for at the same time it is over and it goes on, and is there any tense for that? Watch wound and buried by the watchmaker, before he died, whose ruined works will one day speak of God, to the worms" (BECKETT, 2003, p. 36). ${ }^{11}$

Beckett, então, dá forma à desordem das coisas. O que resta é uma voz angustiada e confusa, resultado do desespero que se encontra suspenso na atmosfera caótica vivenciada no contexto do pós-guerra. E, neste clima de incerteza cada vez mais acentuado, o narrador transita por diversas nuances do comportamento humano. Na segunda parte do livro Molloy, Moran, em sua missão de resgate, apresenta não o processo de imbecilização do indivíduo, como aponta Lukàcs, mas a degradação do sujeito submetido à lógica pequeno-burguesa do capitalismo:

That a man like me, so meticulous and calm in the main, so patiently turned towards the outer world as towards the lesser evil, creature of his house, of his garden, of his few poor possessions, discharging faithfully and ably a revolting function, reining back his thoughts within the limits of the

\footnotetext{
${ }^{9}$ Desconstrução não é um enclausuramento no nada, mas uma abertura em direção ao outro (nossa tradução).

${ }^{10}$ Quem não tem nada é proibido de não gostar da merda (BECKETT, 2007, p. 44).

${ }^{11}$ Minha vida, minha vida, tanto falo dela como de uma coisa acabada, quanto como de uma brincadeira que ainda dura, e estou errado, pois ela acabou e dura ao mesmo tempo, mas com que tempo verbal expressar isso? Relógio com corda nova que o relojoeiro enterra, antes de morrer, e cujo mecanismo retorcido falará um dia de Deus, aos vermes (BECKETT, 2007, p. 60).
} 
calculable so great is his horror of fancy, that a man so contrived, for I was a contrivance, should let himself be haunted and possessed by chimeras, this ought to have seemed strange to me and been a warning to me to have a care, in my own interest (BECKETT, 2003, p. 114). ${ }^{12}$

Como resultado dessas discussões, trazemos para o centro das análises em torno da literatura beckettiana a concepção de uma obra que se distancia enquanto projeção do ideal de sociedade a ser constituída dentro do aspecto moderno, conforme sugerido por Lukàcs quando diz: "é preciso uma cultura literária dirigida para a composição, [...] a fim de que as qualidades excepcionais do homem possam encontrar uma expressão verídica, pessoal e típica” (2010, p. 220). Tampouco, temos a intenção de fazer valer a ótica de um projeto niilista, como argumenta parte dos estudiosos de sua literatura. Entre eles, Bernard Pingaud, Maurice Nadeau e o próprio Lukàcs. O que Beckett constrói é um processo de desmistificação da literatura como algo análogo a uma determinada concepção de realidade. Sua escrita é, em certo sentido, a própria realidade que se apresenta de maneira desvelada; é a visão objetiva de um mundo desprovido de ordem, onde a lógica está a serviço da fragmentação do sujeito, que não mais se identifica com o mundo fetichizado do capitalismo tardio; é o fim da crença iluminista de que, por meio do pensamento, poderíamos dominar a essência da natureza. A realidade do autor é a do fracasso. O mal dizer que expõe a fragilidade da existência, de modo que se materialize na urgência de um caminho diferente, a finitude do homem. Mas de maneira alguma assume a expressão de uma posição niilista: "Naturally I shall do what I can. Meaning, I was born with the disposition to do all I can, all my life I shall do all I can, necessarily" (BECKETT, 2003, p. 104). ${ }^{13}$

Por isso, não vemos os textos do escritor irlandês como a "impotência do vazio", mas "o vazio" como possibilidade. É a metáfora do homem que, perdido no interior de um labirinto, luta para a formulação de um mapa mental que possa revelar a sua saída. Alain Badiou ajuda-nos a compreender essa proposição, quando escreve:

A primeira condição de um dispositivo mínimo para que haja uma questão é decerto que haja o ser puro, cujo nome singular é o vazio. Mas também é preciso haver a exposição do ser, ou seja, não apenas o ser enquanto ser, mas

\footnotetext{
${ }^{12}$ Que um homem como eu, tão meticuloso e calmo em geral, voltado tão pacientemente para o exterior, para com um mal menor, criatura de sua casa, de seu jardim, de alguma de suas pobres posses, fazendo fielmente e com habilidade um trabalho repugnante, conservando o pensamento nos limites de cálculo de tal modo tem horror ao incerto, que um homem assim fabricado, pois eu era uma fabricação, se deixe assombrar e possuir por quimeras, isso devia ter me parecido estranho, e até me levado à ordem ali, no meu próprio interesse (BECKETT, 2007, p. 159).

${ }^{13}$ Farei naturalmente tudo o que puder. Quer dizer, estou disposto a fazer tudo o que puder, farei certamente tudo o que puder sempre (BECKETT, 2007, p. 146).
} 
o ser exposto segundo seu próprio ser, ou a fenomenalidade do fenômeno, ou seja, a possibilidade de que algo apareça em seu ser. E a possibilidade de que algo apareça em seu ser não é o vazio, que, por seu lado, é o nome do ser enquanto ser. $\mathrm{O}$ nome do ser enquanto possibilidade do aparecer é: penumbra (BADIOU, 2002, p. 127).

E a atmosfera acinzentada que se apresenta no decorrer do trabalho beckettiano origina-se dessa penumbra que remete, de maneira constante, à conjuntura marcada pelos conflitos da segunda metade do século XIX, se estendendo até os anos quarenta do século seguinte. Esse contexto leva o fazer literário à necessidade de uma posição antagônica em relação ao realismo naturalista, de maneira mais acentuada, àquelas representações que buscavam uma forma atenuante da realidade sócio-histórica. Com o esgotamento dos esforços progressistas da modernidade e a derrota das revoluções europeias 1847-8, o modernismo surge como essa força de oposição à decadência. Shane Weller, em uma expressão condensada do pensamento de Roger Griffin, elucida:

In short, modernism is a 'revolt against decadence', an attempt both to destroy that which, in the realms of philosophy, politics, and aesthetics, no longer effectively bestows shape and meaning on experience, and to find 'new sources of meaning, spirituality, and communality' (WELLER, 2011, p. 1). ${ }^{14}$

Logo, o que se evidencia com o modernismo, em sentido amplo, é a reação contra uma modernidade que não mais atende aos apelos de sua fase progressista. Em contraposição, Lukàcs, tributário da tradição crítica da modernidade que foi o marxismo, se mantém preso à ideia da realidade como algo dado e passível de apreensão pelo sujeito que a observa. Quando, em sua análise do realismo contemporâneo, critica os adeptos do "modernismo" da avantgarde, o faz em discordância à proposição "the traditional techniques of realism [...] are inadequate, because too superficial, to deal with the realities of our age" $\left(1969\right.$, p. 13). ${ }^{15} \mathrm{O}$ filósofo defende o realismo como forma de superação do irracionalismo e não pensa o modernismo como força de oposição à decadência. Lukàcs prefere acreditar em uma movimentação crítica do realismo enquanto método de orientação do homem para aquilo que se projeta como elemento transformador e emancipatório de uma sociedade revolucionária.

Não concordamos inteiramente com essa posição, mas seu entendimento do processo

\footnotetext{
${ }^{14}$ Em resumo, o modernismo é uma 'revolta contra a decadência', uma tentativa tanto de destruir aquilo que, nos domínios da filosofia, da política e da estética, deixa de atribuir efetivamente forma e significado à existência, como de encontrar 'novas fontes de significado, espiritualidade e comunidade' (nossa tradução).

${ }^{15} \mathrm{O}$ realismo tradicional burguês e suas técnicas de representação são por demais inadequadas e superficiais, diante do caráter absurdo dos eventos que assolam o nosso tempo (nossa tradução).
} 
de decadência define muito bem as contradições do período de ascensão do pensamento reacionário e suas implicações para a literatura como forma de resistência. E é nesse sentido que buscamos desenvolver nossa análise da obra de Beckett. Sua literatura negligencia a certeza indubitável materializada pela herança racionalista, como também renuncia à instrumentalização do pensamento como forma de expressão dessa certeza. "Decidedly this evening I shall say nothing that is not false, I mean nothing that is not calculated to leave me in doubt as to my real intentions. For it is evening, even night, one of the darkest I can remember, I have a short memory" (BECKETT, 2003, p. 211). ${ }^{16} \mathrm{O}$ não dizer presente em seu trabalho está marcado pela obrigação de dizer, mesmo que tal possibilidade não exista. Evidenciando assim não o silêncio, mas o abandono de uma perspectiva ingênua diante de uma realidade devastada por uma linguagem cínica e demagógica.

A decadência da ordem burguesa, que marca a expansão do irracionalismo como corrente dominante da filosofia e da política reacionária a partir dos eventos de 1848, encontra, justamente nessa linguagem a serviço da reificação do pensamento um dos principais instrumentos de difusão do modelo capitalista de sociedade, resultando mais tardiamente no esvaziamento, ou apagamento do referencial histórico e político das obras literárias, tornando-as, assim, alinhadas às ideologias anti-progressistas. É no período da decadência ideológica que a burguesia passa a fomentar o fortalecimento de uma literatura meramente agradável, limitada à reprodução de um mundo conveniente ao imaginário formulado no interior da consciência pequeno-burguesa. Tal movimento servirá como suporte para o aprofundamento dos embates ideológicos da primeira metade do século XX. Sobre esse processo Lukàcs esclarece:

O irracionalismo como concepção do mundo fixa este esvaziamento da alma humana de qualquer conteúdo social, contrapondo-o rígida e exclusivamente ao esvaziamento, igualmente mistificado do mundo do intelecto. Assim, o irracionalismo não se limita a ser a expressão filosófica da barbárie que cada vez mais intensamente domina a vida sentimental do homem, mas a promove diretamente. Paralelamente à decadência do capitalismo e ao aguçamento das lutas de classes em decorrência de sua crise, o irracionalismo apela - sempre mais intensamente - aos piores instintos humanos, às reservas de animalidade e de bestialidade que necessariamente se acumulam no homem em regime capitalista. Se as mentirosas fórmulas demagógicas do fascismo, invocadoras do "sangue e do solo", puderam encontrar uma tão rápida difusão nas massas pequeno-burguesas seduzidas pelo fascismo, é grande a responsabilidade que recai objetivamente sobre a filosofia e a literatura da decadência, [...] (LUKÀCS, 2010, p. 68).

\footnotetext{
${ }^{16}$ Decididamente, esta noite, não direi nada que não seja falso, quero dizer, que não me deixe perplexo quanto as minhas verdadeiras intenções. Pois é tarde, noite mesmo, uma das mais escuras de que me lembro, tenho memória curta (BECKETT, 1983, p. 41).
} 
Diante dessas circunstâncias, Samuel Beckett traz para o centro de suas narrativas o caos, o delírio, o fim do mundo, o sujeito à margem, que assim se posiciona por vontade própria, não havendo uma passividade, muito menos uma alternativa que se apresente razoável a ponto de libertá-lo - se essa é a expressão mais adequada - do estado em que se encontra. "Yes, a world at an end, in spite of appearances, its end brought it forth, ending it began, is it clear enough? And I too am at an end, when I am there, my eyes close, my sufferings cease and I end, I wither as the living can not" (BECKETT, 2003, p. 40). ${ }^{17}$ Se seus personagens apresentam um caráter solitário, antissocial, de modo que as relações entre pessoas assumam uma natureza atormentadora, é porque assim devemos enxergar as relações por trás das máscaras de controle social, impostas pelo sistema avançado do capitalismo. Procedimento que Lukàcs apresenta no ensaio Marx e o problema da decadência ideológica (escrito em 1938):

Não é possível que o homem supere por si mesmo os traços da decadência sem conhecer e compreender as mais profundas estruturas da vida, sem quebrar a casca superficial que, no capitalismo, recobre as ligações mais ocultas e a mais oculta unidade contraditória; aquela casca que a ideologia da decadência mumifica e vende como algo definitivo (LUKÀCS, 2010, p. $81)$.

O que Beckett busca, aparentemente, é nos revelar a realidade how it is, desprovida das cascas criadas como elementos de distração de um mundo arrasado por discursos tautológicos, que, no fim, nos levaram à instrumentalização da barbárie. E, nesse sentido, Malone morre (1951) expõe: "I suppose the wisest thing now is to live it over again, meditate upon it and be edified. It is thus that man distinguishes himself from the ape and rises, from discovery to discovery, ever higher, towards the light" (BECKETT, 2003, p. 255). ${ }^{18}$ Não é possível, consequentemente, compreendermos essa movimentação como niilista.

Faz-se necessário entender, então, que o estranhamento provocado pelo texto beckettiano é resultado, em certa medida, do reconhecimento que temos do mundo e de nós mesmos, representados na atmosfera obscura criada pela obra do autor. Samuel Beckett, por meio da construção de um romance que se apresenta com uma complexidade que lhe é própria, arranca-nos à força do primitivismo fetichista, reflexo do idealismo burguês em seu

\footnotetext{
${ }^{17}$ Sim, é um mundo acabado, apesar das aparências, foi acabado que ele começou, está claro o bastante? Eu também, eu estou acabado, quando estou lá, meus olhos se fecham, meus sofrimentos cessam e acabo, vergado como os vivos não conseguem (BECKETT, 2007, p. 65).

${ }^{18}$ Suponho que a coisa mais esperta agora é reviver a cena, refletir sobre ela e extrair-lhe as lições. É nisso que o homem se distingue dos macacos e ascende, de descoberta em descoberta sempre mais alto, em direção à luz" (BECKETT, 1983, p. 100).
} 
esforço de padronização das relações sociais, marca recorrente das narrativas ao longo da segunda metade do século XIX, e nos coloca imersos diante de uma realidade pautada na instabilidade de um universo criado por incertezas.

Em sua Negative Dialetics (publicado em 1966), Adorno defende que a postura do autor irlandês não se refere, de maneira alguma, ao enaltecimento de uma existência sem significado, mas o contrário: "To Beckett [...] the created world is radically evil, and its negation is the chance of another world that is not yet" $\left(2007\right.$, p. 381). ${ }^{19}$

O que Adorno pretende esclarecer é que Beckett constrói, por meio de sua "estética" da decadência, não a materialização de um modelo de sociedade, como propõe a tradição realista, mas nuances de uma realidade devastada. Sua literatura nega as referências do projeto moderno, configurando o que Shane Weller define como: "a deanial of all enlightment values, including not only universality but also reason and the idea of progress" $(2011, \text { p. } 141)^{20}$, dando ênfase, portanto, à necessidade de encontrarmos uma alternativa, mesmo que indeterminada, para a grande "enrascada" que se configura no desenrolar da modernidade.

Como dito anteriormente, a tradição do romance realista configura um instrumento de manutenção dos valores do pensamento moderno, no qual vemos estabelecido o modelo ordenado pelo narrador onisciente, a traçar perfis de uma sociedade tipicamente burguesa. Samuel Beckett propõe o contrário. Em seus textos, o narrador sofre de uma amnésia atípica. $\mathrm{O}$ apagamento se divide entre o fracasso incorrigível da memória e a impossibilidade de se apreender o caos da realidade que se apresenta de maneira desordenada e imprecisa. Tal movimentação pode ser experienciada, quando lemos: "But what matter whether I was born or not, have lived or not, am dead or merely dying, I shall go on doing as I have always done, not knowing what it is I do, nor who I am, nor where I am, nor if I am" (BECKETT, 2003, p. 226)..$^{21}$

O narrador beckettiano, ao negar o modelo estabelecido pela tradição, traz para o desenvolvimento de suas histórias a construção de uma perspectiva que revele a face decadente do pensamento burguês, expondo a ideia de que toda forma de ilusão se encontra submetida à incerteza. Conforme nos aprofundamos na leitura da trilogia, um nível cada vez mais acentuado dessa oposição ao narrador onisciente se apresenta, a exemplo do trecho que

\footnotetext{
${ }^{19}$ Para Beckett o mundo criado é radicalmente mal, e sua negação é a possibilidade de um outro mundo ainda não existente (nossa tradução).

${ }^{20}$ A recusa de todos os valores do iluminismo, incluindo, não apenas a universalidade, mas também a razão e a ideia de progresso (nossa tradução).

${ }^{21}$ Aliás, pouco importa se eu tenha nascido ou não, se eu tenha vivido ou não, que esteja morto ou apenas moribundo, vou fazer do jeito que sempre fiz, na ignorância do que faço, de quem sou, donde estou, se é que sou" (BECKETT, 1983, p. 64).
} 
destacamos em $O$ inominável (1953): “At no moment do I know what I'm talking about, nor of whom, nor of where, nor how, nor why, but I could employ fifty wretches for this sinister operation and still be short of a fifty-first, to close the circuit, that I know, without knowing what it means (BECKETT, 2003, p. 341). ${ }^{22}$

Sem saber do que fala, de quem fala, de onde fala, nem como, nem porque fala, o narrador beckettiano leva-nos a transitar por uma nova lógica do romance. Sua literatura passa a denunciar o que há de ridículo em obras naturalistas que se apresentam enquanto forma atenuante das misérias do mundo contemporâneo. E, como um referencial que não pode ser ignorado, o irracionalismo surge enquanto corrente filosófica da "desrazão". Por isso, a literatura de Samuel Beckett deve ser lida como a enunciação da necessidade de um caminho diferente, tanto para literatura em sua forma de lidar com as questões da realidade, como também para o homem em sua busca por um caminho que nos apresente um mundo menos superficial.

\section{REFERÊNCIAS}

ADORNO, Theodor. Negative Dialetics. Translated by E. B. Ashton. London: Continuum, 2007.

ANDRADE, Fábio de Souza. Samuel Beckett: O Samuel Beckett. São Paulo: Ateliê Editorial, 2001.

BADIOU, Alain. Pequeno Manual de Inéstética. Tradução de Marina Appenzeller. São Paulo: Estação Liberdade, 2002.

BECKETT, Samuel. Murphy. Tradução de Ana Helena Souza. São Paulo: Cosac Naify, 2013.

BECKETT, Samuel. O inominável. Tradução de Ana Helena Souza; prefácio de João Adolfo Hansen. São Paulo: Globo, 2009.

BECKETT, Samuel. Molloy. Tradução e prefácio de Ana Helena Souza. São Paulo: Globo, 2007.

BECKETT, Samuel. Malone morre. Tradução e posfácio de Paulo Leminsk. São Paulo: Brasiliense, 2. ed., 1986.

BECKETT, Samuel. Molloy, Malone dies, The Unnamable. London: Calder Publications, 2003.

\footnotetext{
${ }^{22}$ Em nenhum momento sei do que estou falando, nem de quem, nem de quando, nem de onde, nem com quê, nem porque, mas teria necessidade de cinquenta forçados para essa lida sinistra e ainda me faltaria um quinquagésimo primeiro, para fechar as algemas, disso eu sei, sem saber o que dizer (BECKETT, 2009, p. 89).
} 
BECKETT, Samuel. Dream of fair to middling women. New York: Arcade Publishing in association with Riverrun Press, 1993.

BECKETT, Samuel. Murphy. London: Calder Publications, 1993.

BERRETTINI, Célia. Samuel Beckett: escritor plural. São Paulo: Perspectiva, 2004.

COUTINHO, Carlos Nelson. O estruturalismo e a miséria da razão. Posfácio de José Paulo Netto. 2 ed., São Paulo: Expressão Popular, 2010.

COUTINHO, Carlos Nelson. Lukàcs, Proust e Kafka: literatura e sociedade no século XX. Rio de Janeiro: Civilização Brasileira, 2005.

LUKÀCS, George. The meaning of contemporary realism. Translated from the German by John and Necke Mander. London: Merlin Press, 1969.

LUKÀCS, George. Marxismo e teoria da literature. Seleção, apresentação e tradução de Carlos Nelson Coutinho. São Paulo: Expressão Popular, 2010.

SCHMIDT, Rita Terezinha. Cultura e Dominação: Pensando (d)as margens In: Descentramento/convergências: Ensaios da Crítica Feminista. Porto Alegre: Editora da UFRGS, 2017. p. 147-165.

WELLER, Shane. Modernism and Nihilism. New York: Palgrave Macmillan, 2011. 